\title{
Statistical Model for Forecasting Area, Production and Productivity of Sesame Crop (Sesamum indicum L.) in Andhra Pradesh, India
}

\author{
N. Priyanka Evangilin ${ }^{1 *}$, B. Ramana Murthy ${ }^{1}$, G. Mohan Naidu ${ }^{1}$ and B. Aparna ${ }^{2}$
}

Department of Statistics and Computer Applications, ${ }^{4}$ Department of Agricultural Economics Acharya N.G. Ranga Agricultural University, S.V. Agricultural College, Tirupati, India

*Corresponding author

\section{A B S T R A C T}

This research study was carried out to fit different Linear, Non - Linear and time series ARIMA models on Area, Production and Productivity of

Keywords

Sesame crop, Area,

Production,

Productivity,

Forecast and ARIMA Model

\section{Article Info}

Accepted:

11 June 2020

Available Online:

10 July 2020
Sesame (Sesamum indicum L.) in Andhra Pradesh for the period 1965-66 to 2017-18. The statistically best fitted model was chosen on the basis of goodness of fit criteria viz. $\mathrm{R}^{2}$, Root Mean Square Error (RMSE) and Mean Absolute Percentage Error (MAPE). Among all the models ARIMA (3, 0, $0)$, ARIMA $(3,0,3)$ and ARIMA $(3,1,1)$ models, were found to be the best fitted models and these models are used to forecast area, production and productivity of Sesame crop in Andhra Pradesh for further five years. The forecasted results showed for area, production and productivity of Sesame crop for the year 2020-21 to be 51.66 thousand hectare, 17.64 thousand tonnes and 323.43 in $\mathrm{kg} /$ hectare respectively. And also it is showed, there is a fluctuated trend on Area and Production and increasing trend on Productivity from the period 2018-19 to 2022-23.

\section{Introduction}

Sesame (Sesamum indicum L.) is the oldest indigenous oilseed crop, with longest history of cultivation in India. Sesame oil is an edible vegetable oil derived from sesame seeds. Sesame or Gingelly is commonly known as til (Hindi, Punjabi, Assamese, Bengali, Marathi), tal (Gujarati), nuvvulu, manchinuvvulu (Telugu), ellu (Tamil, Malayalam, Kannada), tila/pitratarpana (Sanskrit) and rasi (Odia) in different parts of India. Indian people revere sesame and both the oil and seeds are used in traditional cooking methods, religious rituals, Ayurvedic medicine, and topically for skin nourishment. India ranks first in world with 19.47 Lakh ha area and 8.66 Lakh tonnes production. The average yield of sesame (413 $\mathrm{kg} / \mathrm{ha}$ ) in India is low as compared with other countries in the world (535 kg / ha). The main reasons for low productivity of sesame are its rainfed cultivation in marginal and 
submarginal lands under poor management and input starved conditions. However, improved varieties and agro production technologies capable of increasing the productivity levels of sesame are now developed for different agro ecological situations in the country. A well-managed crop of sesame can yield $1200-1500 \mathrm{~kg} / \mathrm{ha}$ under irrigated and $800-1000 \mathrm{~kg} / \mathrm{ha}$ under rainfed conditions. The crop is grown in almost all parts of the country. More than 85\% production of sesame comes from West Bengal, Madhya Pradesh, Rajasthan, Uttar Pradesh, Gujarat, Andhra Pradesh and Telangana.

Narayanaswamy et.al (2012) were fitted statistical models for growth pattern of root and shoot morphological traits in sesame. They have concluded that, the shoot morphological traits growth like mean inter nodal length and shoot dry weight was best explained by the quadratic function, plant height and shoot fresh weight was best explained by the linear function. In root morphological traits growth like root length was best explained by the linear functional form, while root volume, root fresh weight and root dry weight was best explained by the quadratic functional form.

Ramana Murthy et al., (2018) studied the trends of area, production and productivity of Mango crop in Andhra Pradesh from 1992-93 to 2016-17 based on linear and Non-linear statistical models. The results reveal that there is decreasing trend on area and production and gradually increasing trend on productivity of Mango crop in Andhra Pradesh state in above study period.

Sudha et al., (2013) studied to measure the growth trends of area, production and productivity of maize between 1970-71 to 2008-09 and to estimate the future projections up to $2015 \mathrm{AD}$ by using the growth functions like linear, logarithmic, inverse, quadratic, cubic, compound, power and exponential. Based on highest coefficient of determination $\left(\mathrm{R}^{2}\right)$ and its adjusted $\mathrm{R}^{2}$. They concluded that among all the models cubic function was found to be best fitted model for future projections of maize area, production and productivity.

Ramana Murthy et al., (2018) was made an attempt to develop an appropriate ARIMA model for forecasting groundnut area, production and productivity of India. They have concluded that ARIMA $(2,1,3)$, ARIMA $(3,0,3)$ and ARIMA $(2,1,3)$ models were best fitted to forecast area, production and productivity of groundnut in India. For four leading years, they have found that there was a decreasing trend on area and fluctuations on production and productivity from the period 2016-17 to 2019-2020.

Prabakaran et al., (2014) analyzed the Pulses Area and Production in India during the period from $1950-51$ to $2011-12$ by using ARIMA model and he found that ARIMA (1, $1,0)$ and ARIMA $(2,1,1)$ models were best fitted to forecast Pulses Area and Production in India.

The objective of the present study was to fit different linear, non-linear and appropriate Box-Jenkins Auto Regressive Integrated Moving Average (ARIMA) models on area, production and productivity of Sesame crop and to forecast next five years future values based on selected model.

\section{Materials and Methods}

The data of study for a period of 53years (1965-66 to 2017-18) in Andhra Pradesh pertaining to Area ('000 Hectare), Production ('000 tonnes) and Productivity (in $\mathrm{Kg} / \mathrm{Hectare}$ ) of Sesame crop were collected from the source of EPWRF (Economic and Political Weekly Research Foundation) India Time series, Directorate of Economics and 
Statistical and Ministry of Agriculture, Govt. of India in www.indiastat.com. In order to examine the nature of change and degree of relationship in area, production and productivity of Sesame crop in Andhra Pradesh by various linear, non-linear and ARIMA statistical models were worked out by using SPSS 22 version.

\section{Linear and non-linear growth models}

The linear and non-linear growth models for the crop characteristic i.e., Area, Production and Productivity of Sesame crop in Andhra Pradesh are estimated by fitting the following functions.

\section{Auto Regressive Integrated Moving Average (ARIMA)}

The ARIMA methodology is also called as Box-Jenkins methodology (Box and Jenkins 1976). The Box-Jenkins procedure is concerned with fitting a mixed ARIMA model to a given set of data. The main objective in fitting ARIMA model is to identify the stochastic process of the time series and predict the future values accurately. This method shave also been useful in many types of situations which involve the building of models for discrete time series and dynamic systems. However the optimal forecast of future values of a time series are determined by the stochastic model for that series. A stochastic process is either stationary or non-stationary. The first thing to note is that most time series are non-stationary and the ARIMA models refer only to a stationary time series. Since the ARIMA models refer only to a stationary time series the first stage of Box-Jenkins model is for reducing nonstationary series to a stationary series by taking the differences.

The ARIMA (p, d, q) process is given by

$$
y_{t}=\theta_{0}+\phi_{1} y_{t-1}+\phi_{2} y_{t-2}+\phi_{3} y_{t-3}+\ldots \ldots . . .+\phi_{p} y_{t-1}+\varepsilon_{t}-\theta_{1} \varepsilon_{t-1}-\theta_{2} \varepsilon_{t-2}-\theta_{3} \varepsilon_{t-3}-\ldots . . .-\theta_{q} \varepsilon_{t-q}
$$

Where $y_{t}$ and $\varepsilon_{t}$ are the actual value and random error at time period $t$, respectively. $\phi_{i}(i=1,2,3, \ldots . ., p)$ and $\theta_{j}(\mathrm{j}=1, \quad 2$, $3, \ldots \ldots, q)$ are model parameters. $p$ and $q$ are integers and often referred to as orders of the model. Random errors ${ }^{\varepsilon_{t}}$ are assumed to be independently and identically distributed with a mean of zero and a constant variance of $\sigma^{2}$.

The main stages in setting up a Box-Jenkins forecasting model are as follows:

1. Identification 2. Estimating the parameters 3. Diagnostic checking 4. Forecasting

\section{Results and Discussion}

In the present study, the data for Area, production and Productivity of Sesame crop in Andhra Pradesh for the period of 53 years (1965-66 to 2017-18) were used for the study.

\section{Model identification}

Among several models Linear, Non-linear and ARIMA (p, d, q) studies the goodness of fitted models were examined by highest $\mathrm{R}^{2}$ value, lowest RMSE (Residual Mean Square Error)and lowest MAPE (Mean Absolute percentage Error) values. Based on these criterions, it was found that $\operatorname{ARIMA}(3,0,0)$, ARIMA $(3,0,3)$ and $\operatorname{ARIMA}(3,1,1)$ are the best fitted models for forecasting Sesame crop area, production and productivity respectively. The Coefficient of determination $\left(\mathrm{R}^{2}\right)$, Mean Absolute Percentage Error (MAPE) and Residual Mean Square Error (RMSE) are given by

$$
\mathrm{R}^{2}=1-\left[\sum_{t=1}^{n}\left(y_{t}-\hat{y}_{t}\right)^{2} / \sum_{t=1}^{n}\left(y_{t}-\bar{y}\right)^{2}\right]
$$


$\mathrm{MAPE}=\frac{100}{n} \sum_{t=1}^{n}\left|\frac{y_{t}-\hat{y}_{t}}{y_{t}}\right|$

$R M S E=\sqrt{\frac{\sum_{t=1}^{n}\left(y_{t}-\hat{y_{t}}\right)^{2}}{n}}$

Where $y_{t}$ is the actual observation for time period ' $\mathrm{t}$ ' and $\hat{y}_{t}$ is the predicted value for the same period and $\bar{y}_{\text {is the overall sample mean }}$ of observations. The models and the corresponding values are shown in table (1), table (2) and table (3).

\section{Model estimation and verification}

The parameters of the model were estimated by using SPSS 22 package. The
ARIMA (3, 0, 0), ARIMA (3, 0, 3) and ARIMA $(3,1,1)$ were found to be best fitted (3hodels for area, production and productivity of Sesame. The model verification (or) diagnosed by the Ljung-Box Q statistic. The Ljung-Box Q statistic is to check the overall adequacy of the model. The test statistic $\mathrm{Q}$ is given by

$Q_{n}=n r(n r+2) \sum_{l=1}^{n} \frac{r_{l}^{2}(e)}{n r-l}$

Where $r_{l}(e)$ is the residual autocorrelation at lag $l, \mathrm{nr}$ is the number of residual, $\mathrm{n}$ is the number of time lags included in the test for model to be adequate, $\mathrm{p}$-value associated with $\mathrm{Q}$ statistics should be large $(p-$ value $>\alpha)$. The results of estimation are reported in Table 4.

Parametric Trend models

\begin{tabular}{|l|l|}
\hline Model & Functional form \\
\hline Linear function & $y_{t}=a+b t$ \\
\hline Logarithmic function & $y_{t}=a+b \ln (t)$ \\
\hline Inverse function & $y_{t}=a+b / t$ \\
\hline Quadratic function & $y_{t}=a+b t+c t^{2}$ \\
\hline Cubic function & $y_{t}=a+b t+c t^{2}+d t^{3}$ \\
\hline Compound function & $y_{t}=a b^{t}$ \\
\hline Power function & $y_{t}=a t^{b} \quad($ or $) \quad \ln \left(y_{t}\right)=\ln (a)+b \ln (t)$ \\
\hline S- Curve function & $y_{t}=\operatorname{Exp}(a+b / t) \quad($ or $) \quad \ln \left(y_{t}\right)=a+b / t$ \\
\hline Growth function & $y_{t}=\operatorname{Exp}(a+b t) \quad($ or $) \ln \left(y_{t}\right)=a+b t$ \\
\hline Exponential function & $y_{t}=a e^{b t}($ or $) \ln \left(y_{t}\right)=\ln (a)+b t$ \\
\hline
\end{tabular}


Table.1 Linear, Non-linear and Time series models for Area of Sesame crop in Andhra Pradesh

\begin{tabular}{|c|c|c|c|c|c|c|c|}
\hline & \multicolumn{4}{|c|}{ Parameter } & \multicolumn{3}{|c|}{ Criteria } \\
\hline Model & $\mathbf{a}$ & $\mathbf{b}$ & c & d & $\mathbf{R}^{2}$ & RMSE & MAPE \\
\hline Linear & $240.658 * *$ & $-3.113 * *$ & & & $.675^{* *}$ & 33.0220078 & 21.06546 \\
\hline Logarithmic & $302.736 * *$ & $-48.301 * *$ & & & $.544 * *$ & 39.1418826 & 29.85071 \\
\hline Inverse & $141.570 * *$ & $175.040 * *$ & & & $.213 * *$ & 51.4177387 & 41.863751 \\
\hline Quadratic & $221.316^{* *}$ & -1.002 & -.039 & & $.695 * *$ & 31.9943513 & 18.921215 \\
\hline Cubic & $269.986 * *$ & $-11.338^{* *}$ & $.435 * *$ & $\begin{array}{c}- \\
.006 * *\end{array}$ & $.775^{* *}$ & 28.3455185 & 17.90037 \\
\hline Compound & $276.277 * *$ & $.976 * *$ & & & $.629 * *$ & 37.028656 & 22.675628 \\
\hline Power & $408.354 * *$ & $-.347 * *$ & & & $.425^{* *}$ & 48.6003197 & 31.016042 \\
\hline S-Curve & $4.862 * *$ & $1.156 * *$ & & & $.140 * *$ & 57.9152436 & 41.320534 \\
\hline Growth & $5.621 * *$ & $-.024 * *$ & & & $.629 * *$ & 37.028656 & 22.675628 \\
\hline Exponential & $276.277 * *$ & $-.024 * *$ & & & $.629 * *$ & 37.028656 & 22.675628 \\
\hline \multicolumn{8}{|c|}{ Time Series Models } \\
\hline \multicolumn{5}{|c|}{$\operatorname{ARIMA}(\mathbf{1 , 0 , 3 )}$} & 0.790 & 28.203 & 17.533 \\
\hline \multicolumn{5}{|c|}{$\operatorname{ARIMA}(\mathbf{1}, \mathbf{1}, \mathbf{1})$} & 0.763 & 29.277 & 17.669 \\
\hline \multicolumn{5}{|c|}{$\operatorname{ARIMA}(\mathbf{1 , 2 , 1 )}$} & 0.659 & 34.285 & 19.790 \\
\hline \multicolumn{5}{|c|}{$\operatorname{ARIMA}(3,0,0)$} & 0.793 & 27.711 & 17.487 \\
\hline \multicolumn{5}{|c|}{$\operatorname{ARIMA}(2,0,3)$} & 0.780 & 29.194 & 18.712 \\
\hline \multicolumn{5}{|c|}{$\operatorname{ARIMA}(2,2,2)$} & 0.711 & 32.260 & 18.758 \\
\hline \multicolumn{5}{|c|}{$\operatorname{ARIMA}(3,2,2)$} & 0.722 & 31.984 & 17.834 \\
\hline \multicolumn{5}{|c|}{$\operatorname{ARIMA}(\mathbf{3}, \mathbf{1 , 3})$} & 0.779 & 29.491 & 17.914 \\
\hline
\end{tabular}


Table.2 Linear, Non-linear and Time series models for Production of Sesame crop in Andhra Pradesh

\begin{tabular}{|c|c|c|c|c|c|c|c|}
\hline & \multicolumn{4}{|c|}{ Parameter } & \multicolumn{3}{|c|}{ Criteria } \\
\hline Model & $\mathbf{a}$ & b & c & d & $\mathbf{R}^{2}$ & RMSE & MAPE \\
\hline Linear & $40.850 * *$ & $-.395^{* *}$ & & & $.298 * *$ & 9.2792075 & 30.05092 \\
\hline Logarithmic & $50.770 * *$ & $-6.805^{* *}$ & & & $.295 * *$ & 9.29439455 & 30.95508 \\
\hline Inverse & $27.791 * *$ & $27.838 * *$ & & & $.147 * *$ & 10.2256399 & 34.175233 \\
\hline Quadratic & $39.839 * *$ & -.285 & -.002 & & $.299 * *$ & 9.26937772 & 29.71323 \\
\hline Cubic & $53.814 * *$ & $-3.252 * *$ & $.134 * *$ & $.002 * *$ & $.481 * *$ & 7.97996468 & 24.78012 \\
\hline Compound & $41.915^{* *}$ & $.985^{* *}$ & & & $.330 * *$ & 9.42631694 & 28.277905 \\
\hline Power & $57.646 * *$ & $-.238^{* *}$ & & & $.283 * *$ & 9.63411592 & 29.267087 \\
\hline S-Curve & $3.255^{* *}$ & $.919 * *$ & & & $.126^{* *}$ & 10.8263891 & 32.498897 \\
\hline Growth & $3.736^{* *}$ & $-.015^{* *}$ & & & $.330 * *$ & 9.42631694 & 28.277905 \\
\hline Exponential & $41.915^{* *}$ & $-.015^{* *}$ & & & $.330 * *$ & 9.42631694 & 28.277905 \\
\hline \multicolumn{8}{|c|}{ Time Series Models } \\
\hline \multicolumn{5}{|c|}{$\operatorname{ARIMA}(1,1,2)$} & 0.501 & 8.254 & 23.562 \\
\hline \multicolumn{5}{|c|}{$\operatorname{ARIMA}(1,2,3)$} & 0.383 & 8.934 & 24.011 \\
\hline \multicolumn{5}{|c|}{$\operatorname{ARIMA}(2,0,3)$} & 0.579 & 7.715 & 22.831 \\
\hline \multicolumn{5}{|c|}{$\operatorname{ARIMA}(2,1,3)$} & 0.514 & 8.327 & 23.350 \\
\hline \multicolumn{5}{|c|}{$\operatorname{ARIMA}(2,2,3)$} & 0.368 & 9.142 & 24.409 \\
\hline \multicolumn{5}{|c|}{$\operatorname{ARIMA}(3,0,3)$} & 0.621 & 7.400 & 20.876 \\
\hline \multicolumn{5}{|c|}{$\operatorname{ARIMA}(3,1,2)$} & 0.513 & 8.335 & 23.333 \\
\hline \multicolumn{5}{|c|}{$\operatorname{ARIMA}(3,2,3)$} & 0.388 & 9.104 & 24.091 \\
\hline
\end{tabular}


Table.3 Linear, Non-linear and Time series models for Productivity of Sesame crop in Andhra Pradesh

\begin{tabular}{|c|c|c|c|c|c|c|c|}
\hline & \multicolumn{4}{|c|}{ Parameter } & \multicolumn{3}{|c|}{ Criteria } \\
\hline Model & $\mathbf{a}$ & b & c & d & $\mathbf{R 2}$ & RMSE & MAPE \\
\hline Linear & $146.748 * *$ & $2.090 * *$ & & & $.367 * *$ & 41.9919318 & 17.9532 \\
\hline Logarithmic & $128.546^{* *}$ & $24.668 * *$ & & & $.171 * *$ & 48.0526083 & 21.13302 \\
\hline Inverse & $208.208 * *$ & -58.592 & & & .029 & 52.0114761 & 21.950139 \\
\hline Quadratic & $195.068 * *$ & $-3.182 *$ & $.098 * *$ & & $.517 * *$ & 38.6928202 & 15.60092 \\
\hline Cubic & $200.826^{* *}$ & -4.404 & .154 & -.001 & $.518 * *$ & 38.6413231 & 15.59041 \\
\hline Compound & $151.714 * *$ & $1.010 * *$ & & & $.310 * *$ & 41.485376 & 17.438246 \\
\hline Power & $141.165^{* *}$ & $.109 * *$ & & & .135 & 48.0257121 & 20.33387 \\
\hline S-Curve & $5.301 * *$ & -.237 & & & $.019 * *$ & 52.4376734 & 21.173282 \\
\hline Growth & $5.022^{* *}$ & $.010 * *$ & & & $.310 * *$ & 41.485376 & 17.438246 \\
\hline Exponential & $151.714 * *$ & $.010 * *$ & & & $.310 * *$ & 41.485376 & 17.438246 \\
\hline \multicolumn{8}{|c|}{ Time Series Models } \\
\hline \multicolumn{5}{|c|}{$\operatorname{ARIMA}(\mathbf{1 , 0 , 1})$} & 0.477 & 39.701 & 16.209 \\
\hline \multicolumn{5}{|c|}{$\operatorname{ARIMA}(1,1,2)$} & 0.532 & 38.218 & 14.772 \\
\hline \multicolumn{5}{|c|}{$\operatorname{ARIMA}(1,2,1)$} & 0.250 & 48.396 & 19.171 \\
\hline \multicolumn{5}{|c|}{$\operatorname{ARIMA}(2,1,3)$} & 0.519 & 39.601 & 15.360 \\
\hline \multicolumn{5}{|c|}{$\operatorname{ARIMA}(3,0,3)$} & 0.539 & 38.873 & 15.476 \\
\hline \multicolumn{5}{|c|}{$\operatorname{ARIMA}(\mathbf{3 , 1 , 1 )}$} & 0.551 & 37.842 & 14.343 \\
\hline \multicolumn{5}{|c|}{$\operatorname{ARIMA}(3,2,1)$} & 0.304 & 47.649 & 18.461 \\
\hline \multicolumn{5}{|c|}{$\operatorname{ARIMA}(2,2,3)$} & 0.319 & 47.672 & 18.291 \\
\hline
\end{tabular}

1. The value of the criterion for a model with bold numbers shows that the model is better than the other models with respect to that criterion.

2. ${ }^{* *}$, indicates significant at $1 \%$ and $5 \%$ level of probability respectively. 
Table.4 Estimates of the fitted ARIMA $(3,0,0)$, ARIMA $(3,0,3)$ and ARIMA $(3,1,1)$ models for Sesame crop Area, Production and Productivity respectively

\begin{tabular}{|c|c|c|c|c|c|}
\hline \multirow{2}{*}{ Sesame } & \multicolumn{3}{|c|}{ Model fit Statistics } & \multicolumn{2}{c|}{ Ljung-Box Q (18) } \\
\cline { 2 - 6 } & R-Square & RMSE & MAPE & Statistic & p-value \\
\hline Area & 0.793 & 27.711 & 17.487 & 6.952 & 0.959 \\
\hline Production & 0.621 & 7.400 & 20.876 & 14.950 & 0.244 \\
\hline Productivity & 0.551 & 37.842 & 14.343 & 22.577 & 0.068 \\
\hline
\end{tabular}

Table.5 Test for randomness of the residuals for fitted models of Sesame crop Area, Production and Productivity

\begin{tabular}{|l|c|c|c|c|}
\hline \multirow{2}{*}{ Model } & \multicolumn{4}{|c|}{ Run Test for Residuals } \\
\cline { 2 - 5 } & Total Cases & No. of Runs & Z- Value & Sig(2-tailed) \\
\hline Area : ARIMA (3, 0, 0) & 53 & 31 & 0.974 & 0.330 \\
\hline Production : ARIMA (3, 0, 3) & 53 & 30 & 0.696 & 0.489 \\
\hline Productivity: ARIMA (3, 1, 1) & 53 & 21 & -0.969 & 0.333 \\
\hline
\end{tabular}

Table 6: Forecasted values of Sesame crop Area, Production and Productivity with 95\% Confidence Level (CL)

\begin{tabular}{|l|c|c|c|c|c|c|c|c|c|}
\hline \multirow{2}{*}{ Year } & \multicolumn{4}{|c|}{ Area } & \multicolumn{3}{c|}{ Production } & \multicolumn{3}{c|}{ Productivity } \\
\cline { 2 - 12 } & $\begin{array}{c}\text { Forecasted } \\
\text { values }\end{array}$ & LCL & UCL & $\begin{array}{c}\text { Forecasted } \\
\text { values }\end{array}$ & LCL & UCL & Forecasted \\
values & LCL & UCL \\
\hline $\mathbf{2 0 1 8 - 1 9}$ & 44.23 & -11.35 & 99.8 & 10.5 & -3.54 & 24.54 & 304.86 & 230.07 & 379.65 \\
\hline $\mathbf{2 0 1 9}-20$ & 54.19 & -10.97 & 119.34 & 20.63 & 4.73 & 36.54 & 318.67 & 240.88 & 396.46 \\
\hline $\mathbf{2 0 2 0 - 2 1}$ & 51.66 & -14 & 117.32 & 17.64 & 1.28 & 33.99 & 323.43 & 245.51 & 401.36 \\
\hline $\mathbf{2 0 2 1 - 2 2}$ & 47.87 & -18.94 & 114.67 & 20.58 & 4.22 & 36.94 & 325.29 & 246.01 & 404.58 \\
\hline $\mathbf{2 0 2 2}-23$ & 47.72 & -20.74 & 116.18 & 20.95 & 4.47 & 37.43 & 330.61 & 251.18 & 410.04 \\
\hline
\end{tabular}

LCL: Lower Confidence Level, UCL: Upper Confidence Level

Fig.1 Forecasted Sesame crop Area (1965-66 to 2022-23)

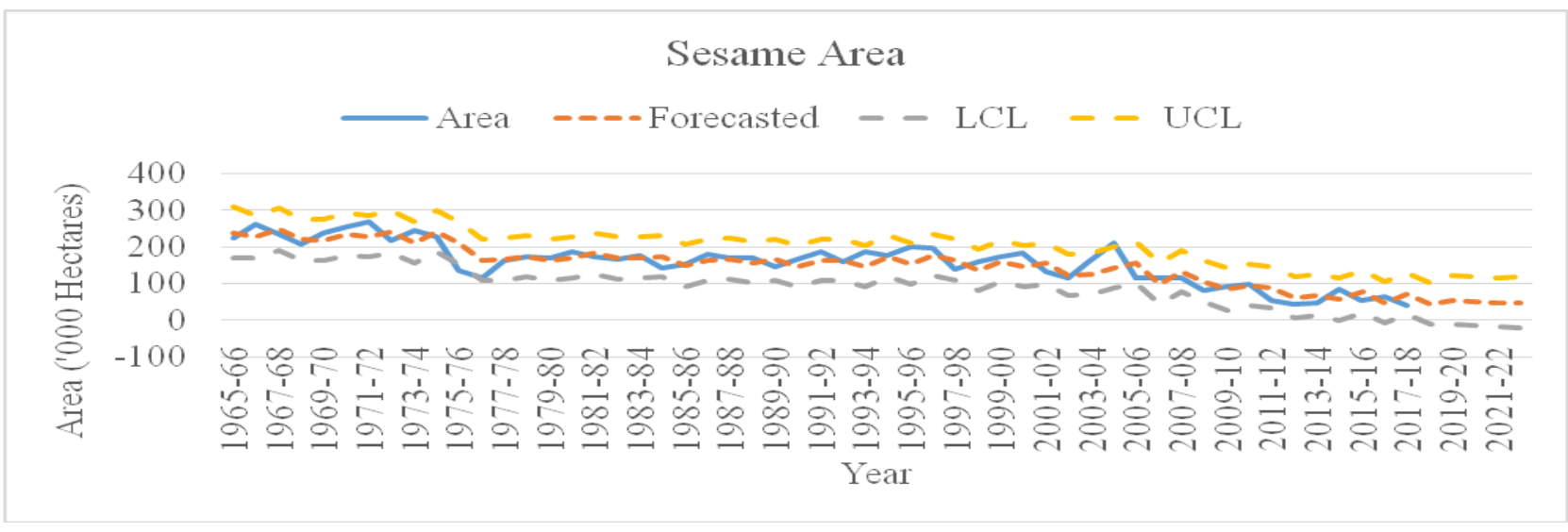


Fig.2 Forecasted Sesame crop Production (1965-66 to 2022-23)

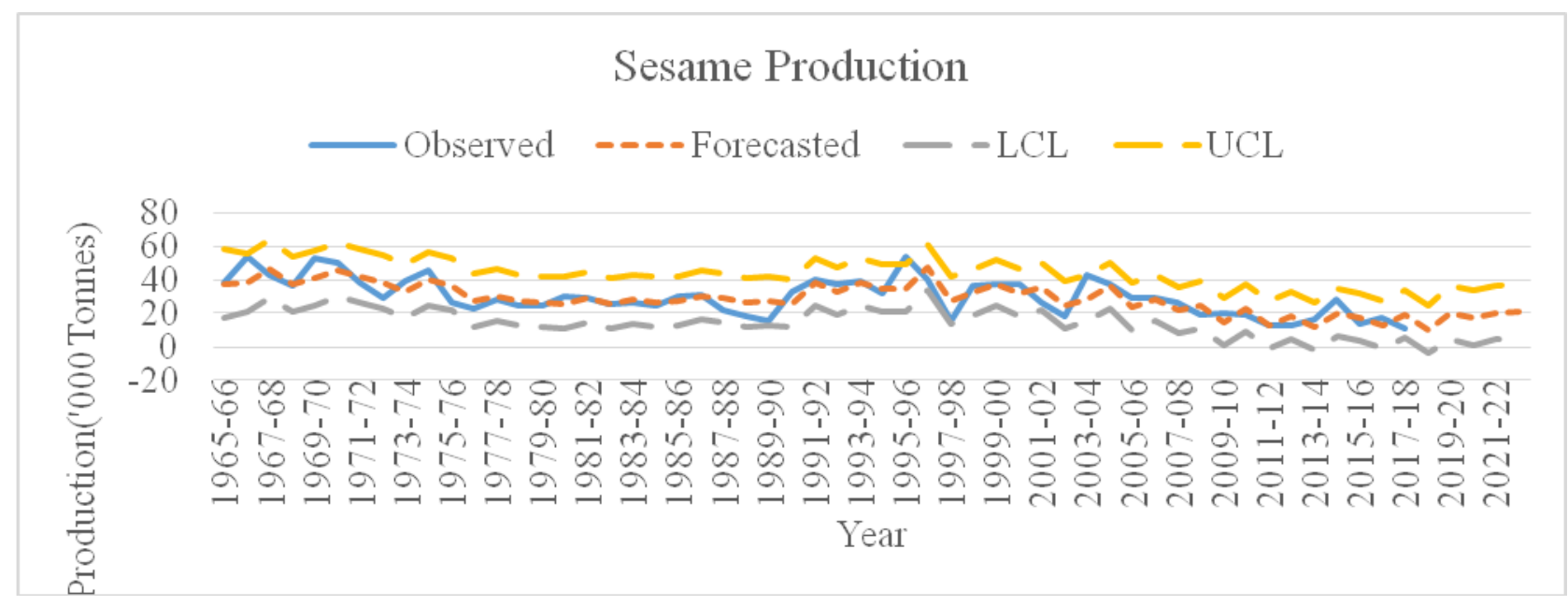

Fig.3 Forecasted Sesame crop Productivity (1965-66 to 2022-23)

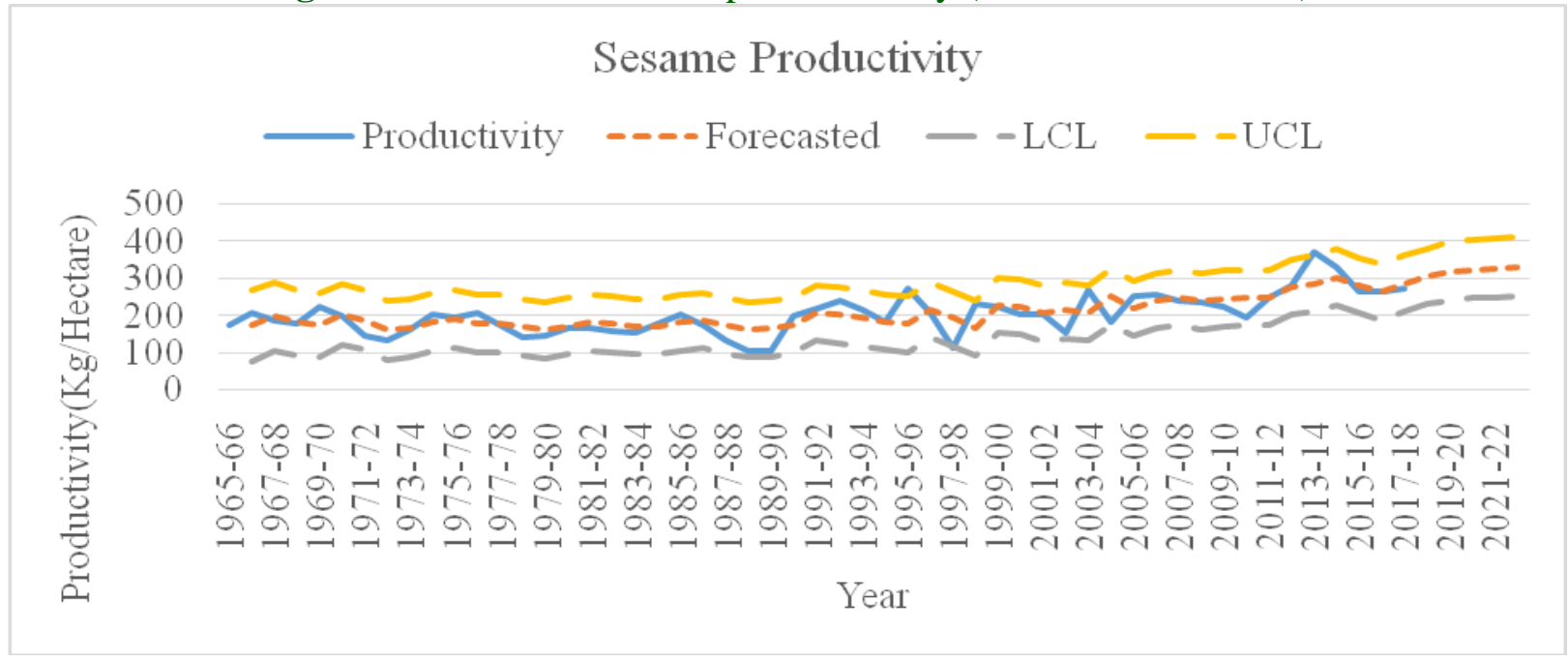

\section{Test for randomness of residuals}

Non-parametric one sample run test can be used to test the randomness of residuals. A run is defined as a succession of identical symbols in which the individual scores or observations originally were obtained. Let ' $n_{1}$ ', be the number of elements of one kind and ' $n_{2}$ ' be the number of elements of the other kind in a sequence of $\mathrm{N}=\mathrm{n}_{1}+\mathrm{n}_{2}$ binary events. For small samples i.e., both $\mathrm{n}_{1}$ and $\mathrm{n}_{2}$ are equal to or less than 20 if the number of runs ' $r$ ' fall between the critical values, we accept the $\mathrm{H}_{0}$ (null hypothesis) that the sequence of binary events is random otherwise, we reject the $\mathrm{H}_{0}$. For large samples i.e., if either $\mathrm{n}_{1}$ or $\mathrm{n}_{2}$ is larger than 20, a good approximation to the sampling distribution of $r$ (runs) is the normal distribution, with mean

$$
\begin{aligned}
& \mu_{r}=\frac{2 n_{1} n_{2}}{N}+1 \text { and standard deviation } \\
& \sigma_{r}=\sqrt{\frac{2 n_{1} n_{2}\left(2 n_{1} n_{2}-n_{1}-n_{2}\right)}{\left(n_{1}+n_{2}\right)^{2}\left(n_{1}+n_{2}-1\right)}}
\end{aligned}
$$


Then, $\mathrm{H}_{0}$ may be tested by

$$
z=\frac{r-\mu_{r}}{\sigma_{r}}
$$

The significance of any observed value of $\mathrm{Z}$ computed from the above formula may be determined by reference to the standard normal distribution table.

\section{Forecasting with ARIMA model}

After the identification of the model and its adequacy check, it is used to forecast the Area, Production and Productivity of Sesame crop for the next five periods. Hence we used the identified ARIMA model to forecast Area, Production and Productivity of Sesame crop for the years 2018-19 to 2022-23. The forecasting results are presented in Table. 6 . And also the diagrams of actual and forecasted values are presented in Figs.1, 2 and 3 .

It is concluded, in the present study the developed ARIMA $(3,0,0)$, ARIMA $(3,0,3)$ and ARIMA $(3,1,1)$ were the best models for forecasting the Sesame area, production and productivity based on $\mathrm{R}^{2}$, RMSE and MAPE criterions in Andhra Pradesh. The study revealed that in coming next five years there is a fluctuations on area and production and increasing trend on productivity of sesame crop in Andhra Pradesh. Sesame seeds have many potential health benefits and have been used in folk medicine for thousands of years. They may protect against heart disease, diabetes, and arthritis. Most of Sesame seed is used for oil extraction which is mainly used for cooking purpose. Thus the agricultural scientist and farmers should take more attention to improve the production and productivity of sesame in Andhra Pradesh.

\section{References}

Box GEP and Jenkin GM (1976), "Time series of analysis, Forecasting and Control", Sam Franscico, Holden Day, California, USA.

Narayanaswami. T., Surendra. H.S., and Santosh Rathod. (2012). Fitting of Statistical Models for Growth of Root and Shoot Morphological Traits in Sesame. Environment \& Ecology, ISSN: 0970-0420, 30 (4): 1362-1365

Prabakaran, K., Nadhiya, P., Bharathi, S. and Isaivani, M., (2014). Forecasting of Pulses area and production in India An ARIMA Approach. Indian Streams Research Journal. 4(3):1-8.

Ramana Murthy. B. and Haribabu.O (2018). A Statistical trend analysis of Mango Area, Production and Productivity in Andhara Pradesh. Int. Journal of Agricultural and Statistical Sciences, 14 (1):337-342.

Sudha, CH. K., Rao, V.S and Suresh, CH. (2013). Growth trends of maize crop in Guntur district of Andhra Pradesh. International Journal of Agricultural Statistical Sciences. 9 (1): 215-220.

Ramana Murthy, B., Mohan Naidu, G., Ravindra Reddy, B., and Nafeez Umar, Sk. (2018). Forecasting Groundnut area, production and productivity of India using ARIMA Model. Int. Journal of Agricultural and Statistical Sciences, 14 (1):153156.

Ramana Murthy. B., Mohan Naidu. G., Tamilselvi.C and PriyankaEvangilin. N. (2020). Validation of ARIMA Model on Production of Papaya in India. Indian Journal of Pure and Applied Biosciences, 8(2), 64-68.

www.epwrfits.in www.indiastat.com. 


\section{How to cite this article:}

Priyanka Evangilin, N., B. Ramana Murthy, G. Mohan Naidu and Aparna, B. 2020. Statistical Model for Forecasting Area, Production and Productivity of Sesame Crop (Sesamum indicum L.) in Andhra Pradesh, India. Int.J.Curr.Microbiol.App.Sci. 9(07): 1156-1166. doi: https://doi.org/10.20546/ijcmas.2020.907.135 